\title{
From a Smart Education Environment to an Eco-School through Fog \& Cloud Computing in IoT Context
}

\author{
Marian STOICA, Marinela MIRCEA, Bogdan GHILIC-MICU, Cristian Răzvan USCATU \\ The Bucharest University of Economic Studies, Bucharest, Romania \\ marians@ase.ro,mmircea@ase.ro,ghilic@ase.ro, cristiu@ase.ro
}

\begin{abstract}
One of the most visible domains of the last decade emerging technological explosion is education. In this paper we will analyze the educational field seen as an intelligent learning environment, in the context of a modern information and communication technology paradigm: fog \& cloud computing. An intelligent educational environment built on the IoT (Internet of Things) ecosystem involves at least two dimensions: conceptual and functional. These aspects will be highlighted in this paper, identifying the intensity of cloud computing relations and fog computing - IoT, as global infrastructure for building an intelligent education environment. In the current economic, social and environmental conditions, developing an intelligent educational frame must take into account multiple aspects. Among them are critical factors, like legal frame, ecological dimension and quality insurance. Any intelligent educational frame must consider the environmental factors and converge towards and ecological structure, an eco-school.
\end{abstract}

Keywords: Fog \& Cloud Computing, Eco-School, Internet of Things, Smart Education, Holistic Approach.

\section{Introduction}

All along the society evolution, the individuals felt the need for knowledge, learning, and education in order to achieve its maximum level of cognitive abilities. The need for learning also includes a professional-social dimension, beyond the personal-creative one. Learning and knowledge generally come from a need to integrate, which manifests on at least four directions (figure 1):

1. Personal;

2. Familial;

3. Professional;

4. Social.

No matter which direction we look into, the individual need for learning is a premise for the development of learning instruments. In this context, the technological revolution initiated in early ' 90 s by the explosion of World Wide Web and general information and communication technology (ICT) has opened new dimensions for daily individual activities. The advantages of ICT adoption in key domains of social development did not take long to manifest and education is one such domain. The space-time paradigm of ICT is becoming a life model with direct implications over the nature of work, education, commerce of governance, providing new opportunities to access information. These technological dimensions are as many premises for approaching the context of an intelligent educational environment, now as more than ever the education has transgressed the boundaries of the classroom and is more and more oriented towards technology. Individual choices and attitudes towards ICT applications seem to be the most important factors in the current evolution of the educational phenomenon. Significant changes will happen only when a large number of people will accept to use the new technological innovations and will allow the insertion of a new behavior in the general field of work, and especially in education. For example, the essential factor that has stimulated the development of telework was the sum of individual choices and attitudes. The next significant phase in the development of the phenomenon will be supported by the organizations with progressive views. Many of the basic society areas will be gradually affected, as time passes and intelligent environments spread more and more and become more widely used, both in intensity and number of users. The domains susceptible to be affected and for which effects will be seen in different moments in time are travels 
and transportation; ambient design; physical environment planning; social, cultural and commercial services; educational structures; work and social relations; regional (structural) development.

The foundation for the effects that can be observed and anticipated in this domain derives from the changes in organizational forms generated by new ICT applications. Travels and traveling behavior is a field where new habits will be relatively soon visible because normally it does not take a huge effort to adapt to new transportation habits (see intelligent transport). Interior design using the instruments of domotics and imotics for new houses or for adaptation of existing ones will become gradually visible, according to individual requests, being implemented where and when it is called upon. For new constructions it is a bit more complicated because on one hand it will take a while for new approaches to be adopted and on the other hand it will take long until these approaches will be really applied in building new houses, intelligent and ecological. The other domains mentioned above will probably be affected later and undoubtedly it will take longer to see significant effects on regional level, as development innovations. From this point of view, many people lay their hopes on the possibility that ICT improves the competitiveness of distant regions. On medium term there will be changes in other domains, from social relations to physical environment planning [7].

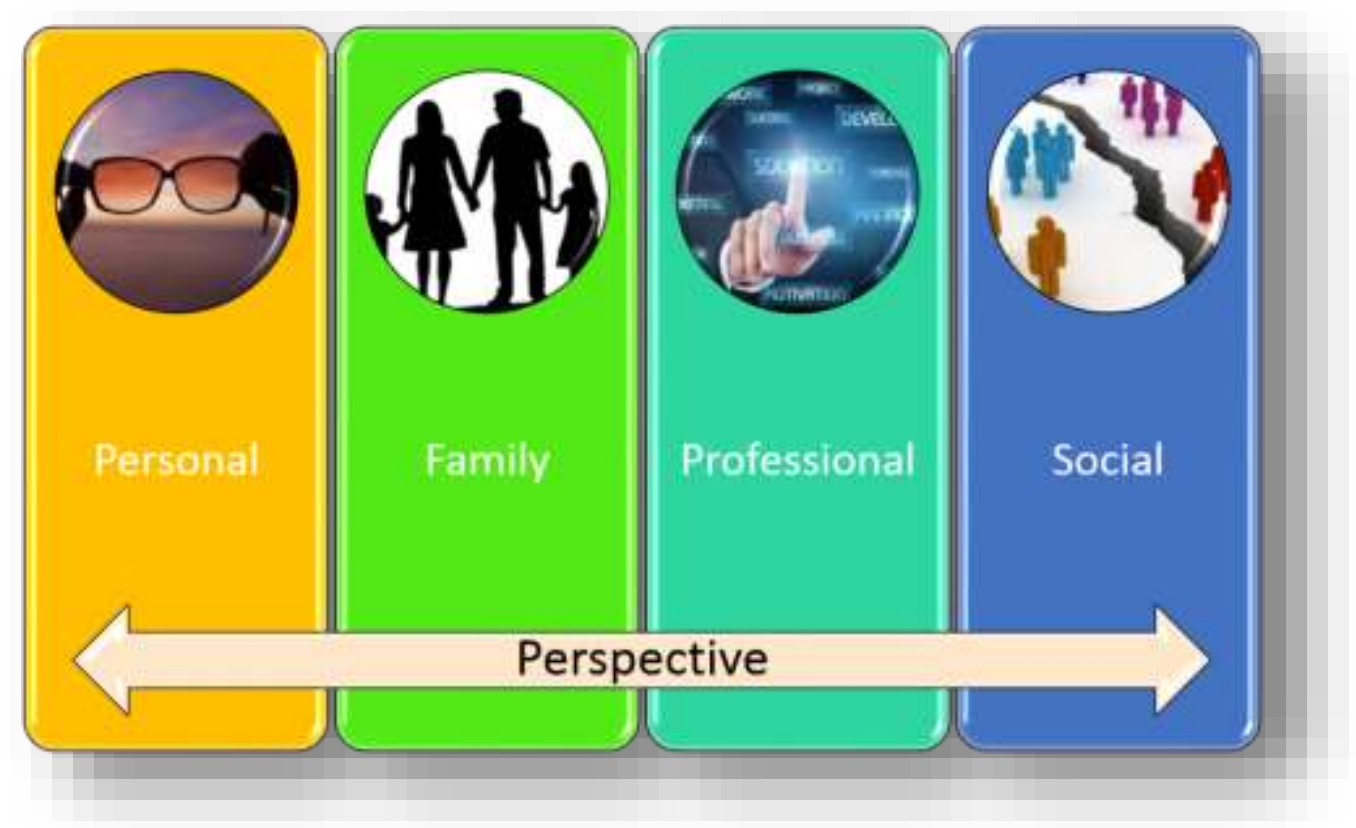

Fig. 1. Dimensions of need for integration through learning

Additionally, most technological developments may be perceived as true revolutions in this field, most significant of them being the intelligent mobile communications. From this perspective alone we can speak today not only about intelligent education environments or intelligent cities, but also about dimensions that impact the environment - learning ecology, ecologic programming, green programming, ubiquitous / pervasive learning etc.
Unfortunately, for a national education system a holistic approach of education as a whole cannot be implemented in terms of ecological intelligent environments. Instead, we can approach punctual aspects, oriented on projects not on system. Thus, we can see how advanced technology adopted by the educational environment stimulates the orientation towards personalized learning processes, focused on the student. General distance learning solutions like e-learning satisfy more or 
less this approach. Accomplishing such a personalized educational process may only be done in the context of intelligent educational environments. Considering the holistic paradigm and the big picture, designing and implementing these intelligent environments must take into account, as previously stated, concerns related to quality assurance and protection of the environment (ecology).

\section{Dimensions of an intelligent educational environments}

The main elements that must be highlighted when designing an intelligent educational environment must target two dimensions:

1. Terminological dimension and definitions of specific concepts and

2. Technological and functional dimension of designing and implementing the solution.

To cover the first dimension we propose a parallel approach of traditional education vs. intelligent education or intelligent educational environment. In a traditional environment, the educational processes have a rather unidirec- tional repartition, in a well-defined geographical space (the classroom). The main actors are the teachers as main source of information and students, all being in the same place and participating at the same time to the same activities.

In the second perspective, an intelligent educational environment introduces a third main actor: ICT. In such a ubiquitous learning stance, technology creates the possibility for activities to be performed in separate time and space for each participant, teacher or student. The technology imprints a new vision for education, redesigns it. In this context, the literature does not provide a unanimously accepted definition of intelligent education (smart learning). Even more, in professional academic environments and main multidisciplinary research, the concept is still being debated. An educational space must provide elements of task individualization, theme personalization and formative negative/positive feedback both for student and teacher. Thus, in an intelligent educational environment, the pedagogical strategy must include and support at least four directions (see Table 1).

Table 1. Support directions for an intelligent educational environment

\begin{tabular}{|c|l|l|}
\hline Nr.crt. & Support direction & \multicolumn{1}{c|}{ Meaning } \\
\hline 1 & Conversation, dialog & $\begin{array}{l}\text { The educational environment must provide the stu- } \\
\text { dent with the ability to participate in conversation of } \\
\text { group discussions on relevant subjects. }\end{array}$ \\
\hline 2 & Reflection, thought & $\begin{array}{l}\text { The educational environment must provide instru- } \\
\text { ments for student self-assessment based on progress } \\
\text { and performance, suggesting activities and skills that } \\
\text { should be improved for a better general performance. }\end{array}$ \\
\hline 3 & $\begin{array}{c}\text { Innovation, original- } \\
\text { ity, creativity }\end{array}$ & $\begin{array}{l}\text { The educational environment must rely on modern } \\
\text { and innovative technologies to support instruction. }\end{array}$ \\
\hline 4 & $\begin{array}{c}\text { Self-organization, } \\
\text { self-control }\end{array}$ & $\begin{array}{l}\text { The educational environment must include the ability } \\
\text { to rearrange resources and control mechanisms in or- } \\
\text { der to improve its performance over time, to refine } \\
\text { the way it interacts with participants under various } \\
\text { conditions. }\end{array}$ \\
\hline
\end{tabular}


Designing and implementing an intelligent educational environment must consider the four directions, considering the functional components. The technological perspective seems accessible on a first glance: spectacular development in the recent years, materialized in numerous "technological revolutions" is an admissible premise for defining an adequate infrastructure. These technological revolutions (mobile communications, intelligent devices, environmental intelligence, cloud computing, fog computing etc.) together with the intense digitization of daily individual activities places him in an original environment, generally called Internet of Things (IoT). Among the emergent technologies that may be invoked to build an intelligent learning environment in the context of IoT we must certainly consider the cloud computing and fog computing. In this context we must see the intelligent education environment as a superior form of information society manifestation in the ecosystem defined by IoT. Thus, the smart environment surpasses the open environment, which in turn follows to a virtual education environment.

A comprehensive approach of education as a whole or a holistic perspective of the phenomenon will have to include aspects related to assurance and environment protection. In the Romanian system, for example, the education quality assurance methodology is based on the relations between components like criteria, standards and reference standards, performance indicators and qualifications. In this regards, education quality assurance is implemented through processes like planning and achieving the expected results, monitoring the results, internal and external evaluation of results and continuous improvement of education outcomes. In a real education environment, components and processes for quality assurance as well as the relations between them as differentiated on the education level and, if needed, type of qualification, type education providing organization and type of study program [9][10]. Romanian organizations charged with quality assurance in the educational system are ARACIP (Romanian Agency for Quality Assurance in High school
Education) and ARACIS (Romanian Agency for Quality Assurance in Higher Education).

\section{Cloud Computing and IoT}

In order to perceive correctly the extent of the relation between Cloud Computing and the IoT, we should imagine a symbiotic technology-information context generated by the two paradigms. Although the original term refers to two or several different entities (species, in scientific terminology), Cloud Computing and the IoT may work interdependently, supporting each other. Moreover, this mutually beneficial "cohabitation" breeds symbiotic products, such as CoT or Cloud IoT. In the light of what the IoT is today and the obviously expansionist trends in technology, Cloud Computing acquires new dimensions, materialized in field-dedicated services. So, at the height of the information and knowledge-based society it is worth highlighting several important aspects of Cloud Computing if we want to understand these new dimensions. The most endorsed definition of cloud computing is the one given by national Institute of Standards and Technology (NIST) though NIST Special Publication 800-145 of 25th October 2011 (after two years of research) and describes a convenient model that allows access on request, through network (internet) to a group of configurable computation resources (for example networks, servers, storage equipment, platforms, applications and services) that can be provided to the user fast, with minimal administration effort or interaction with the provider of such resources [1].

Cloud Computing may create the feeling that it has infinite power, as scalability and the multi-tenant management regime of virtual resources can at all times allow for their allocation/de-allocation based on the needs of the clients. In the light of IoT, Cloud Computing may be perceived as a type of utility computing. In essence, however, there are three things which are necessary to define an IoT node: intelligence, sensing and wireless communication. Beyond these aspects, the main IoT components may be identified in physical 
and virtual objects, sensors and actuators, individuals and services, communication platforms and networks [1].

These new dimensions of cloud computing (CoMaaS (CoMmunication), CoNaaS (CoNtainers), DaaS (Desktop), OaaS (Outsourcing), MoNaaS (Monitoring), MeTaaS (MeTal), XaaS (Anything or Everything as a Service) - see [1]) are real premises for the definition of an intelligent education environment. Of course, in this context we can invoke a dedicated dimension for intelligent education environments: SEaaS - Smart Education as a Service.

Beyond these dimensions, it is widely known that the cloud computing paradigm was adopted in intelligent educational environments under the generic name of Cloud-learning [6]. The adoption of Cloud-learning is based on the fundamental concepts of informational society [7], expressed as domotics and imotics concepts of the late 90s. Modern approaches have embedded fundamental concepts in what the literature (and much less the practice) calls Ambient Intelligence (AmI). The hybrid combination of ambient intelligence and cloud learning is a solution for the intelligent educational environment. Synthesizing the technical aspects, we can conclude that this intelligent environment provides as main functionality the reuse of educational resources in a distributed manner through cloud features. As technological solution, the best suited approach must be oriented towards private cloud solutions, considering the rising accent on personalized learning [8].

\section{Fog Computing and IoT}

In the context of cloud computing, extending the data storage capacities and data analyses facilities is a support for global interconnection of human existence universes. Additionally, the premise of this networked technological infrastructure is a good foundation for developing dynamic and efficient services for businesses. Internet of Things connects real life objects through a large variety of technologies, devices and protocols. Besides the benefits of IoT, it comes with problems and challenges related to scalability, interoperability, efficiency, availability, storage and security [2]. All these aspects, together with the peculiarities of cloud development support the development of fog computing, which is supported by big software development companies like Cisco Systems, Dell, Intel or Microsoft through OpenFog Consortium since November 2015.

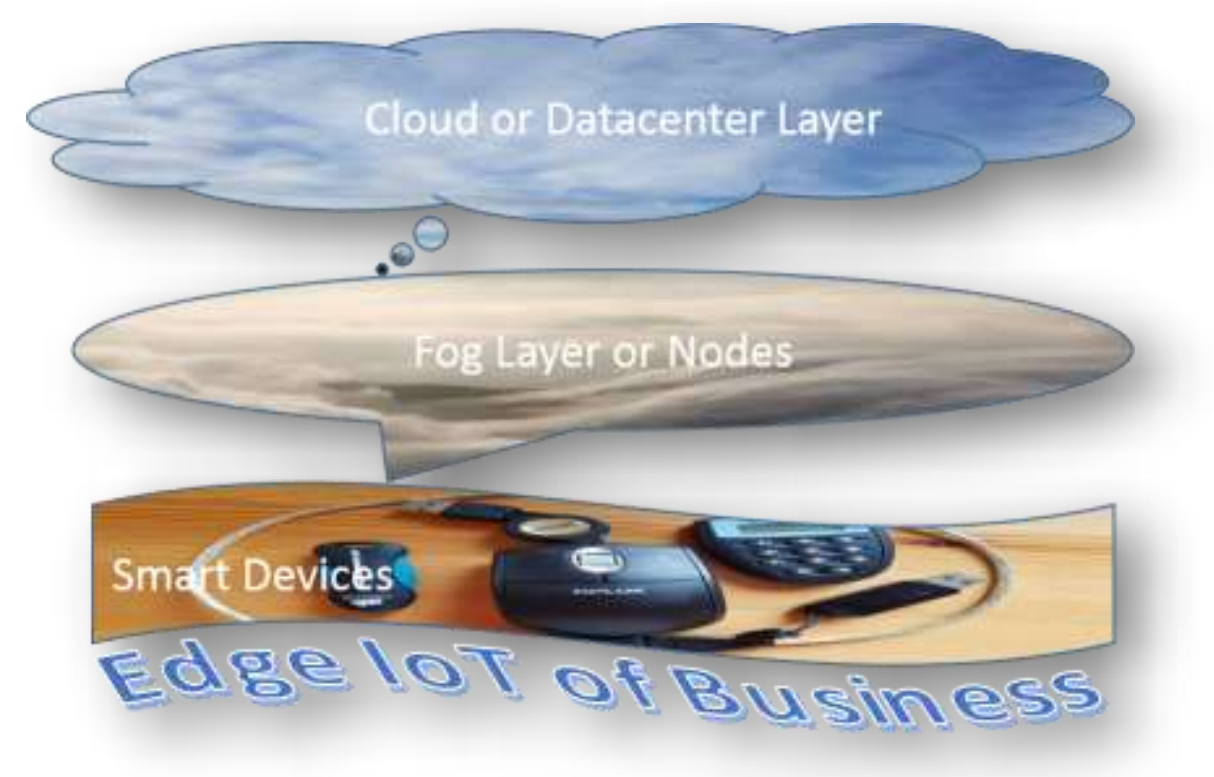

Fig. 2. Fog extends the cloud to the place where data is created 
Both cloud and fog provide final users with storage, applications and data services. The fog is closer to end users, with a greater geographical distribution. Created by Cisco, fog computing means extending the cloud to the edge of an organization network. Also known as edge computing or fogging, it facilitates the functioning of computing, storage and networking services between final devices and data centers. While edge computing usually refers to the place where services are accessed, the fog involves distributing the resources and communication, computing and storage services on or near the devices and systems controlled by the final users (figure 2).

Similar to gathering stage in the lifecycle of data, the fog brings the data processing resources closer to the place where they are created. While the process of gathering data and information seeks to ensure their authenticity and precision, in fog computing we can speak of a greater agility of business, security level or reduced cost of business operations [3].

\section{A hybrid approach for a smart education environment}

The diversity of applications developed in a hybrid cloud-fog computing approach reaches the complexity level expected from IoT. The common factor is monitoring and analyses of data in real time, leading to an action related to an element of IoT - a device, a sensor or an intelligent agent. With multiple possibilities, the action can manifest as a M2M paradigm (machine to machine) or a HMI paradigm (human machine interaction).

The functional elements of an intelligent educational environment may be at the edge of a cloud-fog computing. Beside the general characteristics that must be considered (scalability, interoperability, reliability, efficiency, availability, storage and security) we must also look at the specific elements of the intelligent education environment. According to [5] they materialize in 10 key aspects that must simultaneously define and characterize an intelligent education environment:
1. Location-aware: in intelligent learning real time location creates important data required to adapt the content and the process to the student;

2. Context-aware: exploring various activity and information scenarios;

3. Socially-aware: adaptation to social relations;

4. Interoperability: establishing standards for various resources, services and platforms;

5. Default connection: providing continuous services for any device connected;

6. Adaptability: use of learning resources based on preferences, access and demand;

7. Ubiquity: anticipation of student needs before a clear request, providing visual and transparent access to learning services;

8. Full traceability: recording data about learning habits and in-depth analyses, providing a fair assessment, suggestions and on-demand service;

9. Natural interaction: transfer of multimodal interaction, senses, including face and expression recognition;

10. Total immersion: multi-directional interactive learning experiences in highly technological environments.

Most of the times, designing and implementing intelligent learning environments goes beyond applying existing technologies. An intelligent learning environment must allow the students to access digital resources and interact with learning systems anytime and anywhere. Additionally, it must provide (inter)active suggestions, instruments and solutions needed in the right location and in correct shape [6]. Real time location is important for adaptation of the content and the process to the student. Still, the location is not always a necessary condition in intelligent learning. The most important characteristic is for the system to be able to advise and anticipate student needs. All these functional aspects of an intelligent educational environment may be implemented using a hybrid cloud-fog computing approach (figure 3). 


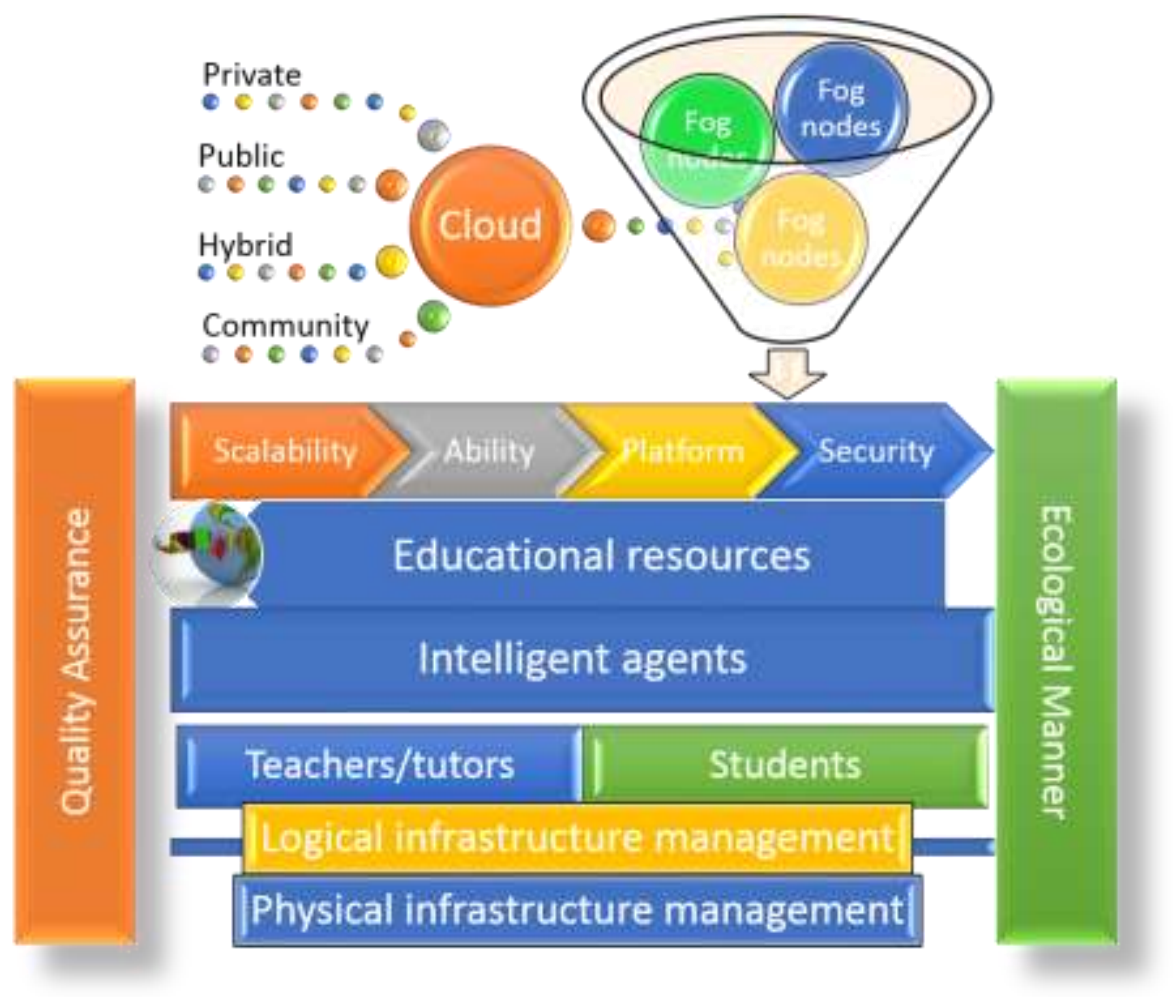

Fig. 3. A hybrid approach for a smart education environment

An intelligent educational environment in a hybrid cloud-fog computing approach must possess both cloud specific features and fog computing feature, which mainly bring the storage and development environment (educational resources) closer to the intelligent agents (dedicated to teachers and students). The functional foundation must include primitives and infrastructure for management of logical and physical components.

\section{The path to eco-school}

A holistic approach of the educational environment in the context of IoT and intelligent learning environments must target also the environment aspects and its protection. There are two dimensions to this approach. First, there is the actual educational dimension through which the education organization provides students with information and knowledge regarding environment protection. This activity must not be reduced to simple presentation of general elements regarding ecology. It must be accompanied by artefacts meant to raise students' awareness regarding the negative effects of pollution. The so called green fascism must be tackled by convincing the masses that a new world order will be ecological or not at all [11]. Second, we must consider what the education organization does to protect the environment and move towards an eco-school. Not so far ago, ecological schools were a fantasy. In the last decade, as new ecological materials and building supplies were created, new eco construction technologies were developed and improved and there was a measurable raise in the awareness regarding the environment importance. Thus, improved and more ecological design choices were adopted for education buildings. There are a series of international examples that come to promote the concept of eco-school and stimulate intelligent educational environments through adoption of ecological design in education buildings [12].

Nanyang Technical University of Singapore (figure 4) certainly has a uniquely striking visual identity. It has a green grass roof and raises up to five levels, with plenty of light coming through large windows. The building is incredibly energy efficient due to the design and swirl effect of the half circle architecture, which reduces the loss of heat. The green roof 
has more than an aesthetic role: it ensures insulation and a durable ecosystem.

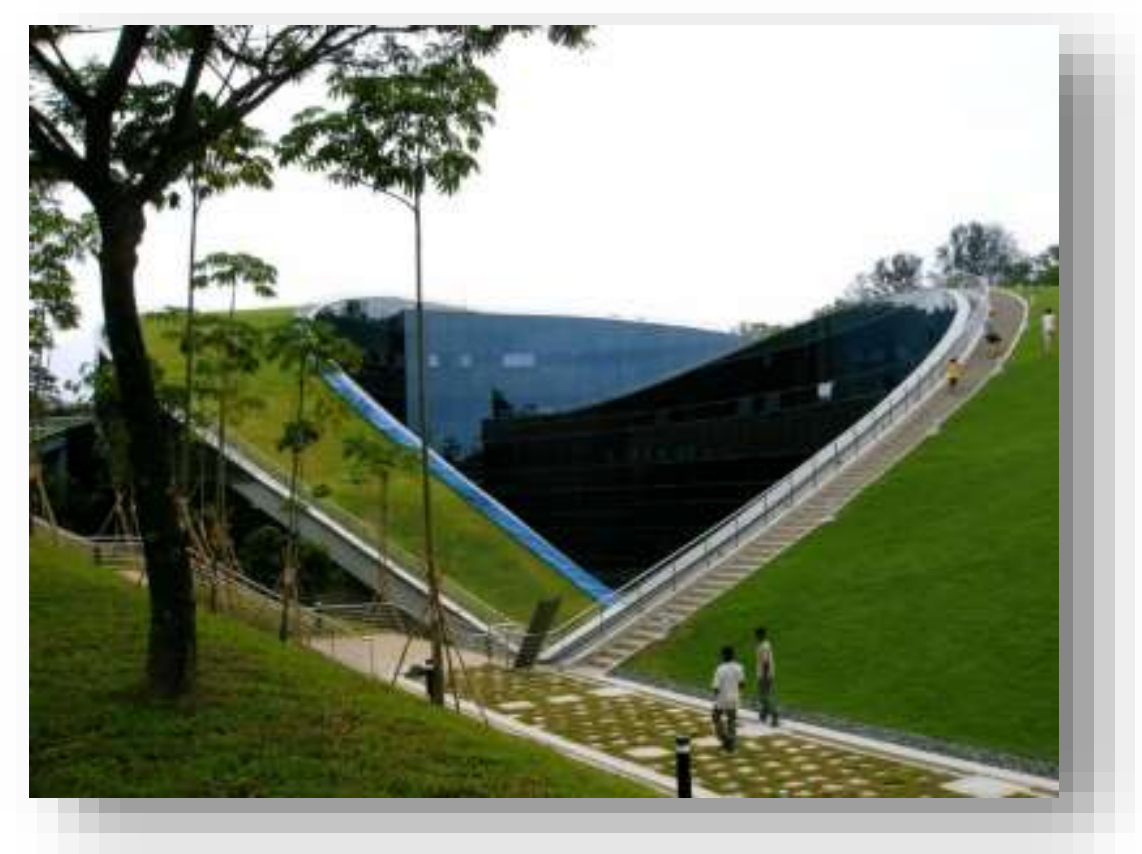

Fig. 3. Eco-school at Nanyang Technical University, Singapore

Other such accomplishments are the Green Mountain College of Poultney, Vermont, USA, where students created various ecological spots based on biomass and photovoltaic solar panels. Also in Vermont, there is the Sterling College of Craftsbury Common, an ecological campus where students tend to products and animals of the college farm. The California University of Irvine, USA, is not a strange to ecological design: it used its campus for experimenting with energy efficient technologies. In 2017 the university has implemented the first project involving the use of excess energy from renewable sources to inject hydrogen into natural gas for use in power plants. The excess energy from its 17 solar installations is used to extract hydrogen from water, mix it with gas than store this fuel for later use.

\section{Conclusions}

Lifelong learning has long ago ceased to be a novelty, just like access to education anywhere, anytime. An intelligent educational environmental must integrate formal and informal education to shape the adaptive profile of a student centered environment. Just like the anthropocentric approach of modern management, intelligent educational systems must focus on individual performance, not on the system performance. In the end, the system will concentrate the integrated, synergic result of individual performances and a hybrid cloudfog approach has all the premises for success. Unfortunately, no matter how many intelligent educational we would imagine, there is an acute global trend regarding the main raw material of the educational process: the students. This aspect must be corroborated with the resistance of a significant part of the educational personnel regarding the use of technology and especially intelligent equipment. These aspects act in opposition to the optimism perceived in the field of intelligent education environments. Additionally, the educational phenomenon must be completed with quality assurance and environment protection components. If the hybrid cloud-fog approach brings the specific characteristics (scalability, ability to provide resources, security etc.) to the intelligent educational environment, the components dealing with quality assurance 
and environment protection must be implemented through specific procedures and campaigns of raising the awareness, both for students and teachers. This is the context that opens the path to intelligent educational environments, to eco-schools.

\section{References}

[1] B. Ghilic-Micu, M. Mircea, M. Stoica, QAaaS in a Cloud IoT Ecosystem, Revista Informatica Economică vol. 21, nr. 4/2017, pp. 5-14, http://revistaie.ase.ro/content/84/01\%20$\% 20$ ghilic, \%20mircea,\%20stoica.pdf

[2] M. Mircea, M. Stoica, B. Ghilic-Micu, Using Cloud Computing to Address Challenges Raised by the Internet of Things, in Connected Environments for the Internet of Things, Springer Verlag 2017, pp. 6382, ISBN 9783319701011

[3] Cisco Systems, White Paper, Fog Computing and the Internet of Things: Extend the Cloud to Where the Things Are, Cisco Public 2015, Available: https://www.cisco.com/c/dam/en_us/solutions/trends/iot/docs/computing-overview.pdf, [March 25, 2018]

[4] Begoña Gros, The design of smart educational environments, in Smart Learning Environments, Springer Verlag 2016, Available: nal.springeropen.com/articles/10.1186/s40561-016-0039-x, [March 21, 2018]

[5] J. Michael Spector, Smart Learning Environments: Concepts and Issues, Conference Paper, Savannah, GA, United States, March 21-26, 2016, Available: https://www.researchgate.net/publication/301612985_Smart_Learning_Environments_Concepts_and_Issues, [March 22, 2018]

[6] Manuel Sánchez, Jose Aguilar, Jorge Cordero, Priscila ValdiviezoDíaz, Luis Barba-Guamán, Luis Chamba-Eras, Cloud Computing in Smart Educational Environments: Application in Learning Analytics as Service, Conference Paper, Springer International Publishing Switzerland 2016, Available: https://link.springer.com/chapter/10.1007\%2F978-3-319-31232-3_94, [June 17, 2018]

[7] B. Ghilic-Micu, M. Stoica, eActivităţile în societatea informaţională, Ed. Economică, Bucureşti, 2002, ISBN 973-590-5892

[8] S.M.Barhate, Snehal Narale, Cloud Based Teaching and Learning Environment for Smart Education, International Journal on Recent and Innovation Trends in Computing and Communication, Volume: 3 Issue: 2, February 2015, ISSN: 2321-8169, pp. $38-41$

[9] ARACIP - http://beta.aracip.eu/Resurse/Manuale, $\% 20$ ghiduri\%20si\%20instrumente $\% 20$ de $\% 20$ evaluare

[10] ARACIS - http://www.aracis.ro/cadrullegislativ/ii-cadrul-legislativ-referitor-lainvatamantul-superior-din-romania/

[11] Călin Ștefănescu, Educație ecologică, https://www.scribd.com/doc/38913623/E ducatia-Ecologica, [July 4, 2018]

[12] 4 Eco School Designs, http://beis.uk/en/education/4-eco-schooldesigns/, June 9, 2018

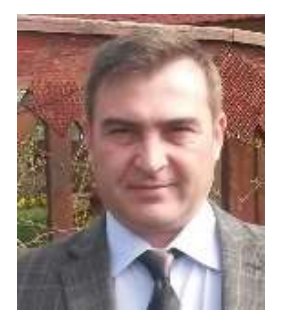

Marian STOICA received his degree on Informatics in Economy from the Bucharest University of Economic Studies in 1997 and his doctoral degree in economics in 2002. Since 1998 he is teaching in Bucharest University of Economic Studies, at Informatics and Cybernetics Economy Department. His research activity, started in 1996 and includes many themes, focused on management information systems, computer programming and information society. The main domains of research activity are Information Society, E-Activities, Tele-Working, and Computer Science. The finality of research activity still today is rep- 
resented by over 80 articles published, 25 books and over 40 scientific papers presented at national and international conferences. Since 1998, he is member of the research teams in over 30 research contracts with Romanian National Education Ministry and project manager in 5 national research projects.

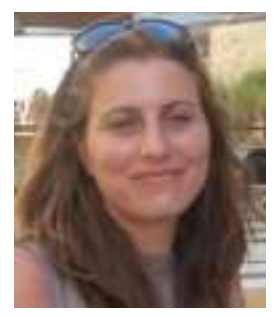

Marinela MIRCEA received her degree on Informatics in Economy from The Bucharest University of Economic Studies, Bucharest in 2003 and his doctoral degree in economics in 2009. Since 2003 she is teaching in Academy of Economic Studies from Bucharest, at Informatics and Cybernetics Economy Department. Her work focuses on the programming, information system, business management and Business Intelligence. She published over 40 articles in journals and magazines in computer science, informatics and business management fields, over 30 papers presented at national and international conferences, symposiums and workshops, she was member over 15 research projects and project manager in 2 national research projects. She is the author and co-author of 12 books. In February 2009, she finished the doctoral stage, and her $\mathrm{PhD}$ thesis has the title Business management in digital economy.

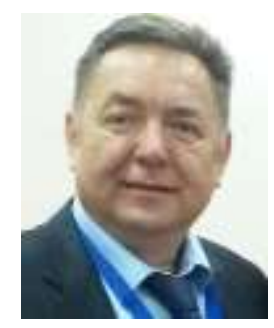

Bogdan GHILIC-MICU received his degree on Informatics in Economy from the Academy of Economic Studies Bucharest in 1984 and his doctoral degree in economics in 1996. Between 1984 and 1990 he worked in Computer Technology Institute from Bucharest as a researcher. Since 1990 he teaches in The Bucharest University of Economic Studies from Bucharest, at Informatics in Economy Department. His research activity, started in 1984 includes many themes, like computers programming, software integration and hardware testing. The main domain of his last research activity is the new economy - digital economy in information and knowledge society. Since 1998 he managed over 25 research projects like System methodology of distance learning and permanent education, The change and modernize of the economy and society in Romania, E-Romania - an information society for all, Social and environmental impact of new forms of work and activities in information society.

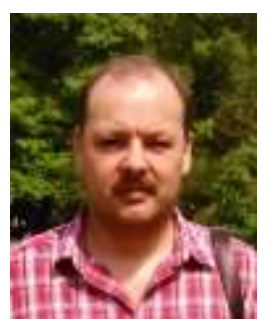

Cristian Răzvan USCATU received his degree on Informatics in Economy from The Bucharest University of Economic Studies, Bucharest in 1997 and his doctoral degree in economics in 2007. In the present he is Associated Professor, $\mathrm{PhD}$, currently working with the Bucharest University of Economic Studies, Faculty of Cybernetics, Statistics and Informatics, Department of Informatics and Cybernetics in Economy. Competence areas: computer programming, data structures. Author/co-author of more than 10 books and 40 papers published in national and international journals. 